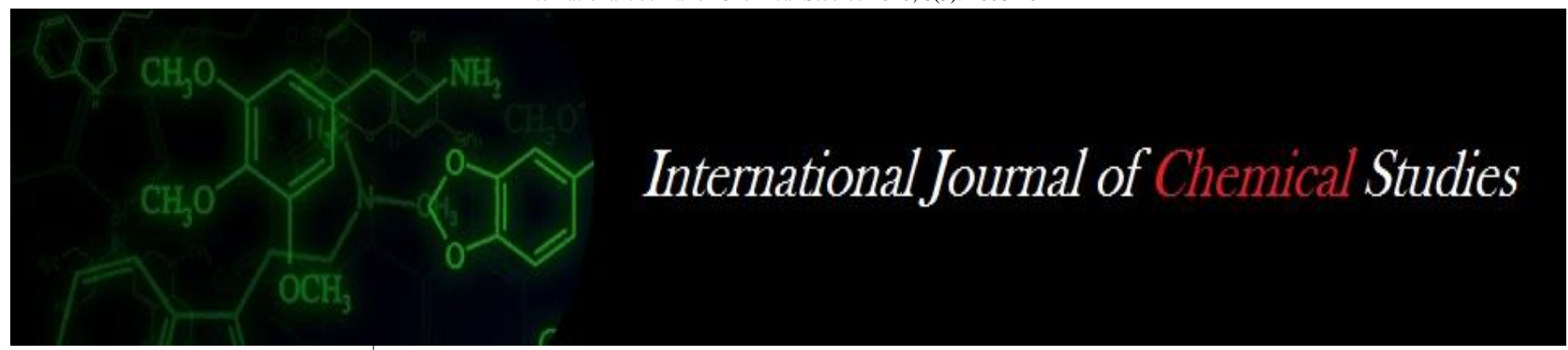

P-ISSN: 2349-8528

E-ISSN: 2321-4902

www.chemijournal.com

IJCS 2020; 8(5): 2608-2611

(C) 2020 IJCS

Received: 21-07-2020

Accepted: 23-08-2020

\section{Tejas Korde}

M.Sc. Student, Dept. of

Horticulture, G H Raisoni

University, Saikheda, Tq.

Saunsar Dist. Chhindwara

Madhya Pradesh, India

Dr. Archana Khadse

Asstt. Professor, Dept. of

Horticulture, G H Raisoni

University, Saikheda, Tq.

Saunsar Dist. Chhindwara,

Madhya Pradesh, India

Dr. Ashish Sarda

Associate Professor, Dept. of

Statistics, G H Raisoni

University, Saikheda, Tq.

Saunsar Dist. Chhindwara,

Madhya Pradesh, India
Corresponding Author: Tejas Korde

M.Sc. Student, Dept. of

Horticulture, G H Raisoni

University, Saikheda, Tq.

Saunsar Dist. Chhindwara

Madhya Pradesh, India

\section{Effect of media and PGR on rooting and survival of air layered pomegranate plants (Punica Granatum L)}

\author{
Tejas Korde, Dr. Archana Khadse and Dr. Ashish Sarda
}

DOI: https://doi.org/10.22271/chemi.2020.v8.i5aj.10712

\begin{abstract}
The present study entitled "Effect of Media and Growth Regulators on rooting and survival of air layered Pomegranate Plants (Punica granatum L)" was conducted during the year 2019-20 at School of Agricultural Sciences, G. H. Raisoni University, Dhoda Borgaon, Saikheda. Dist. Chhindwara, M. P. The material was sown in Completely Randomized Design with three replications and 7 treatments. The treatments were Soil (control) (Black soil), Soil + IBA 2000 ppm, Soil + NAA 2000 ppm, Coco peat + IBA 1000ppm, Coco peat + NAA 1000ppm, Saw dust + IBA 1000ppm and Saw dust + NAA 1000ppm. The result indicated that the Coco peat with IBA 1000 ppm was best combination giving the best rooting, survival and was economical too.
\end{abstract}

Keywords: Effect of media, (Punica Granatum L), Growth Regulators

\section{Introduction}

Pomegranate (Punica granatum L.) is an ancient favorite table fruit of tropical and sub-tropical regions of the world. It belongs to the family punicaceae which includes only one genus and two species, the other being P. protopunica Balf (Socotra pomegranate). Growing of pomegranate is one of the most profitable cultivating ventures in India. It is a great yield for growing under dry and semi-dry conditions as it endures dry spell and unfavorable climatic condition. Despite the fact that pomegranate is developed partially in chosen areas in numerous states. It is grown in Maharashtra, Gujarat, Karnataka, Andhra Pradesh, Uttar Pradesh, Rajasthan and Tamil Nadu on a large scale. The total pomegranate production on the planet is 10 lakh tones. India produces 5 lakh tones from a region of about 25,000 ha but export just 5000 tones, though Spain produces 1 lakh tone and export 75,000 tons and their export closes by December. (Annon, 2006-07). Distinctive media like sphagnum greenery, coco peat and saw dust have higher dampness holding limit with lighter weight, which improve root arrangement. The exogenous utilization of IBA and NAA instigates establishing stem cuttings; because of their capacity to enact in cambium recovery, cell division and cell augmentation. Root lengthening additionally recorded with the use of auxin.

\section{Methodology}

The present study entitled was conducted during the year 2019-20 at School of Agricultural Sciences, G. H. Raisoni University, Dhoda Borgaon, Saikheda. Dist. Chhindwara, M. P.

\section{Plant material}

The pencil size thick one year old mature shoots of pomegranate were selected for growing at Horticultural research farm, at School of Agricultural Sciences, G. H. Raisoni University, Dhoda Borgaon, Saikheda Dist. Chhindwara, M. P.

\section{Air layering material}

The experiment required four types of rooting media viz. soil (black soil collected from selected field), coco peat and saw dust. For wrapping of air layers polythene paper pieces of $\mu$ gauge were used and for tying of air layers sutali was used. 
Poly bags (4" x 6") were used for planting air layers, to study the survival of air layers.

\section{Observations recorded}

Days required for visible initial appearance of root, Day required for visible bulk appearance of root, Number of primary roots at 45 th day, Number of secondary roots at 45 th day, Maximum root length $(\mathrm{cm})$ at 45 th day, Fresh root weight $(\mathrm{g})$ at 45 th day, Dry root weight $(\mathrm{g})$ at 45 th day, Survival (\%) of air layers 45 days after in the poly bags, Length of shoot $(\mathrm{cm}) 45$ and 60 days after transplanting in the poly bags, Number of leaves 45 and 60 days after transplanting in the poly bags, Leaf area $(\mathrm{cm} 2) 45$ and 60 days after transplanting in the poly bags, Number of branches at 45 and 60 days after transplanting in the poly bags.

\section{Statistical Procedures}

The statistical analysis of data recorded during the experiment was carried in Completely Randomized Design as described by Panse and Sukhatme (1967) ${ }^{[5]}$ and differences in treatment mean were compared by critical difference at $5 \& 1$ per cent level.

\section{Results and Discussion}

A nursery trial was conducted during the kharif season in the year 2019-20 to study the Effect of media and growth regulators on rooting and survival of air layered Pomegranate Plants. The data pertaining to the initiation of root as influenced by different media and PGR's are presented in Table 1. It is reveled from the data presented in the Table 1 that rooting media had influenced significantly the appearance of root and causing earliness in rooting of air layers. The mean days required for initial appearance of root in air layer ranged from 16.00 to 21.67 days. Significantly minimum number of days (16.00) was required for rooting of air layers in Coco peat + IBA 1000 ppm followed by saw dust + IBA $1000 \mathrm{ppm}$ and Soil + NAA $2000 \mathrm{ppm}$. The maximum numbers of days (21.67) were required for rooting air layering in soil alone. This might be due to low moisture holding capacity of soil as compare to other media and absence of root initiating chemicals in media. The early root initiation with the use of coco peat might be due to higher water holding capacity and good aeration. But there might be little compactness when saw dust and soil were used as rooting media. These results are in agreement with Chatterjee (1981) ${ }^{[1]}$ who found that coco peat was the best rooting medium in case of air layer and Divekar (1984) ${ }^{[2]}$ who reported cocopeat was the best rooting medium in air layer of Karonda.

The perusal of data regarding days required for bulk appearance of roots presented in Table 1 reveled that Soil + NAA $2000 \mathrm{ppm}$ recorded the significantly minimum number of days (26.33) for bulk appearance of root followed by Coco peat + IBA 1000 ppm followed by Saw dust + IBA 1000ppm and Soil + NAA 2000 ppm which recorded (28.67) days for bulk appearance of roots. These treatments were at par with Coco peat + NAA 1000ppm and Saw dust + NAA 1000ppm. The maximum numbers of days (35) were recorded in soil alone treatment. In respect of PGR result revealed that IBA had a more pronounced effect on rooting than NAA. Tyagi and Patel (2004) ${ }^{[8]}$ studied the combination of IBA and NAA which was more effective with higher concentration.

The data regarding number of primary roots at 45 days after air layering as influenced by different rooting media are presented in Table 1 . Number of primary roots at 45 days per air layer was significantly influenced by different treatments. The number of primary roots ranged from 5 to 13 . Significantly maximum number of primary roots (13) was observed with treatment of Coco peat + IBA 1000 ppm followed by Saw dust + IBA 1000 ppm (10.67) and Saw dust + NAA 1000 ppm (9.33). These treatments were at par with each other also. The minimum number of primary roots (5) was observed with treatment; soil alone. Among the plant growth regulators IBA $1000 \mathrm{ppm}$ and among media coco peat performed well. This might be due to favorable factor for root growth in media viz. higher moisture holding capacity and aeration, which enhanced the bulkiness of roots. These results are in conformity with Chatterjee (1981) ${ }^{[1]}$, Kumar et al. (2004) ${ }^{[4]}$ and Tyagi and Patel (2004) ${ }^{[8]}$.

Table 1: Effect of media and PGR on different part of Plant at 45 Days

\begin{tabular}{|c|c|c|c|c|c|c|}
\hline Treatment & \begin{tabular}{|c|}
$\begin{array}{c}\text { No. of Primary } \\
\text { Roots }\end{array}$ \\
\end{tabular} & $\begin{array}{c}\text { No. of Secondary } \\
\text { Roots }\end{array}$ & $\begin{array}{c}\text { Max Root } \\
\text { Length }\end{array}$ & $\begin{array}{c}\text { Fresh Root } \\
\text { Weight }\end{array}$ & $\begin{array}{c}\text { Dry Root } \\
\text { Weight }\end{array}$ & $\begin{array}{c}\text { Survival } \\
\%\end{array}$ \\
\hline T1- Soil (control) (Black soil) & 5.33 & 21.00 & 4.33 & 0.13 & 0.13 & 51.46 \\
\hline T2 - Soil + IBA 2000 ppm & 9.00 & 35.00 & 8.00 & 0.68 & 0.25 & 73.66 \\
\hline T3 - Soil + NAA 2000 ppm & 8.33 & 33.33 & 6.00 & 0.24 & 0.17 & 62.40 \\
\hline T4 - Coco peat + IBA 1000ppm & 13.00 & 40.67 & 12.00 & 0.90 & 0.31 & 82.35 \\
\hline T5 - Coco peat + NAA 1000ppm & 8.67 & 36.67 & 8.00 & 0.80 & 0.24 & 70.08 \\
\hline T6 - Saw dust + IBA 1000ppm & 10.67 & 40.67 & 8.33 & 0.86 & 0.28 & 77.51 \\
\hline T7 - Saw dust + NAA 1000ppm & 9.33 & 31.33 & 6.00 & 0.79 & 0.20 & 66.35 \\
\hline SEm \pm & 0.78 & 1.96 & 0.75 & 0.07 & 0.01 & 1.46 \\
\hline C.D. at $5 \%$ & 2.36 & 5.94 & 2.26 & 0.20 & 0.04 & 4.42 \\
\hline $\mathrm{CV} \%$ & $14.64 \%$ & $9.96 \%$ & $17.16 \%$ & $18.55 \%$ & $10.23 \%$ & $3.66 \%$ \\
\hline
\end{tabular}

Maximum number of secondary roots (40.67) was recorded with Coco peat + IBA 1000ppm and Saw dust + IBA 1000 ppm followed by Coco peat + NAA 1000ppm (36.67) which were at par with each other. The minimum number of secondary roots (21.00) was recorded in soil alone treatment. These results are in conformity with those reported by Tryamabke and Patil (2002) ${ }^{[7]}$ Kumar et al (2004) ${ }^{[4]}$ and Tyagi and Patel (2004) ${ }^{[8]}$. 
Table 2: Effect of Media and PGR on different part of Plant at 45 and 60 Days

\begin{tabular}{|c|c|c|c|c|c|c|c|c|}
\hline Treatment & \begin{tabular}{|c|}
$\begin{array}{c}\text { Length of } \\
\text { shoots }\end{array}$ \\
\end{tabular} & $\begin{array}{c}\begin{array}{c}\text { Length of } \\
\text { shoots }\end{array} \\
\end{array}$ & $\begin{array}{c}\text { No of } \\
\text { Leaves }\end{array}$ & $\begin{array}{c}\text { No of } \\
\text { Leaves }\end{array}$ & $\begin{array}{c}\text { Leaf Area } \\
\text { (cm2) }\end{array}$ & $\begin{array}{c}\text { Leaf Area } \\
(\mathrm{cm} 2)\end{array}$ & $\begin{array}{c}\text { Number of } \\
\text { Branches }\end{array}$ & $\begin{array}{c}\text { Number of } \\
\text { Branches }\end{array}$ \\
\hline & 45 Days & 60 Days & 45 Days & 60 Days & 45 Days & 60 Days & 45 Days & 60 Days \\
\hline T1- Soil (control) (Black soil) & 35.05 & 35.05 & 39.33 & 39.33 & 12.97 & 12.97 & 4.33 & 4.33 \\
\hline T2 - Soil + IBA 2000 ppm & 42.70 & 42.70 & 49.00 & 49.00 & 19.57 & 19.57 & 6.00 & 6.00 \\
\hline T3 - Soil + NAA 2000 ppm & 40.64 & 40.64 & 47.67 & 47.67 & 16.27 & 16.27 & 4.00 & 4.00 \\
\hline T4 - Coco peat + IBA 1000ppm & 47.25 & 47.25 & 54.67 & 54.67 & 21.30 & 21.30 & 7.33 & 7.33 \\
\hline T5 - Coco peat + NAA 1000ppm & 43.03 & 43.03 & 47.67 & 47.67 & 18.23 & 18.23 & 6.33 & 6.33 \\
\hline T6 - Saw dust + IBA 1000ppm & 39.59 & 39.59 & 42.67 & 42.67 & 20.43 & 20.43 & 7.00 & 7.00 \\
\hline T7 - Saw dust + NAA 1000ppm & 37.54 & 37.54 & 34.67 & 34.67 & 17.23 & 17.23 & 4.00 & 4.00 \\
\hline SEm \pm & 1.58 & 1.58 & 1.50 & 1.50 & 0.65 & 0.65 & 0.65 & 0.65 \\
\hline C.D. at $5 \%$ & 4.80 & 4.80 & 4.54 & 4.54 & 1.97 & 1.97 & 1.99 & 1.99 \\
\hline $\mathrm{CV} \%$ & $6.71 \%$ & $6.37 \%$ & $5.75 \%$ & $5.75 \%$ & $6.24 \%$ & $6.24 \%$ & $20.35 \%$ & $20.35 \%$ \\
\hline
\end{tabular}

The average maximum root length was recorded in the treatment Coco peat + IBA 1000ppm $(12 \mathrm{~cm})$ followed by Saw dust + IBA 1000ppm $(8.33 \mathrm{~cm})$, Soil + IBA 2000 ppm $(8.00 \mathrm{~cm})+$ Coco peat + NAA 1000ppm $(8.00 \mathrm{~cm})$ and Soil + NAA $2000 \mathrm{ppm}+$ Saw dust + NAA 1000ppm $(6.0 \mathrm{~cm})$ these treatments were at par with each other. The minimum root length $(4 \mathrm{~cm})$ was observed in the treatment soil alone. The minimum root length was observed in the air layering done using soil as media. This might be due to absence of PGR and reduced water availability compared to moss. These results are in conformity with those reported by Tryamabke and Patil (2002) ${ }^{[7]}$ and Tyagi and Patel (2004) ${ }^{[8]}$.

Maximum weight of fresh root was observed in the air layers prepared with Coco peat + IBA 1000ppm (0.90 g) followed by Saw dust + IBA 1000ppm (0.86 g), Coco peat + NAA $1000 \mathrm{ppm}(0.80 \mathrm{~g})$. These treatments were at par with each other. In media and PGR combination sawdust + NAA 1000 ppm recorded the least fresh weight of roots this might be due to consequences of compactness of sawdust as compared to coco peat and soil. These results are in conformity with those reported by Tryamabke and Patil (2002) ${ }^{[7]}$ and Kumar et al (2004) ${ }^{[4]}$.

Significantly maximum dry root weight $(0.31 \mathrm{~g})$ at 45 days was observed in Coco peat + IBA 1000ppm followed by and on at par with Saw dust + IBA 1000ppm (0.28 g), Soil + IBA 2000 ppm (0.25 g), Coco peat + NAA 1000ppm (0.24 g) \& Saw dust + NAA $1000 \mathrm{ppm}(0.20 \mathrm{~g})$. The least dry weight of roots was recorded in soil alone $(0.13 \mathrm{~g})$. Minimum dry root weight was observed in the air layering with soil alone this was observed due to compact nature of media with low water holding capacity. These results are in conformity with those reported by Tryamabke and Patil (2002) ${ }^{[7]}$ and Kumar et al (2004) ${ }^{[4]}$.

The maximum survival percentage $(82.35 \%)$ was recorded with Coco peat + IBA 1000ppm followed by $77 \%$ survival in the treatment Saw dust + IBA 1000ppm, $70 \%$ in Coco peat + NAA 1000ppm, $73 \%$ in Soil + IBA 2000 ppm while it was minimum $(51.46 \%)$ in soil alone. The survival percentage was recorded in poly bags than in soil. The optimum concentrations of IBA have increased the rooting characters which resulted in higher survival percentage. The results are

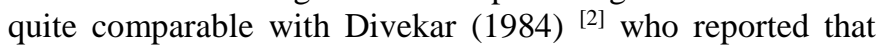
the coco peat was the best rooting medium for air layering in karonda.

The maximum length of shoots at 45 and 60 days after transplanting were recorded as Coco peat + IBA 1000ppm (47.25 and 53.14) respectively followed by (43.03 and 46.99) whereas the Soil + IBA 2000 ppm, Soil + NAA 2000 ppm, Saw dust + IBA 1000ppm, Saw dust + NAA 1000 ppm is at par with each other while the minimum length of shoot was recorded in soil alone (35.05 and 40.08). These results are in conformity with those reported by Tryamabke and Patil (2002) ${ }^{[7]}$ and Kumar et al (2004) ${ }^{[4]}$.

The results at 45 days showed significantly maximum number of leaves (54.67) under the treatment Coco peat + IBA 1000 ppm followed by Soil + IBA 2000 ppm (49.00), Soil + NAA 2000 ppm (47.67), Coco peat + NAA 1000ppm (47.67) and Saw dust + IBA 1000 ppm (42.67). These treatments were at par with each other. This might be due to early initiation of roots, more number of roots, root length which affected the number of leaves after transplanting. These results are comparable with those reported by Sobhana et al (1995) ${ }^{[6]}$, Bhagat et al (1999) Tyagi and patel (2004) ${ }^{[8]}$.

The results at 60 days showed significantly maximum number of leaves (68.67) under the treatment Coco peat + IBA 1000ppm followed by Soil + IBA 2000 ppm (59.67), Saw dust + IBA 1000ppm (58.33), Soil + NAA 2000 ppm (57.00) and Coco peat + NAA 1000ppm (55.00). These treatments were also at par with each other. The least number of leaves recorded at 45 days (34.67) under the treatment Saw dust + NAA 1000 ppm and at 60 days (50.00) were recorded under the treatment Soil (control) (Black soil). Maximum area by leaf under the treatment Coco peat + IBA 1000 ppm followed by Saw dust + IBA 1000 ppm as rooting media. This might be happened due to better porosity of coco peat and positive impact of IBA for root growth. These results are in conformity with those reported by Tryamabke and Patil (2002) ${ }^{[7]}$ and Tyagi and Patel (2004) ${ }^{[8]}$.

The results at 45 days showed significantly maximum area by leaf (21.30) under the treatment Coco peat + IBA 1000ppm followed by Saw dust + IBA 1000ppm (20.43), Soil + IBA 2000 ppm (19.57), Coco peat + NAA 1000ppm (18.23) and Saw dust + NAA 1000ppm (17.23). These treatments were at par with each other.

The results at 60 days showed significantly maximum leaf area covered by leaves (25.23) under the treatment Coco peat + IBA 1000 ppm followed by Saw dust + IBA 1000ppm (24.40), Soil + IBA 2000 ppm (23.17), Coco peat + NAA 1000ppm (21.87) and Saw dust + NAA 1000ppm (21.27). These treatments were also at par with each other. The least leaf area was recorded at 45 days (12.97) and at 60 days (14.83) under the treatment Soil (control) (Black soil) alone.

The results at 45 days showed significantly maximum number of branches (7.33) under the treatment Coco peat + IBA $1000 \mathrm{ppm}$ followed by Saw dust + IBA 1000ppm (7.00), Coco peat + NAA 1000ppm (6.33), and Soil + IBA 2000 ppm (6.00). These treatments were at par with each other.

The results at 60 days showed significantly maximum number of branches (10.33) under the treatment Coco peat + IBA 1000 ppm followed by Saw dust + IBA 1000 ppm (10.00), 
Soil + IBA 2000 ppm (8.00), Coco peat + NAA 1000 ppm (7.67) and Saw dust + NAA 1000ppm (7.00). These treatments were also at par with each other. The least number of branches was recorded at 45 days (4.00) under the treatment Saw dust + NAA 1000ppm where as in 60 days (4.33) was recorded under the treatment Soil (control) (Black soil) alone. The results at 60 days showed significantly maximum number of branches under the treatment Coco peat + IBA 1000 ppm followed by Saw dust + IBA 1000 ppm. This might be happened due to better porosity of coco peat and positive impact of IBA for root growth. These results are comparable with those reported by Sobhana et al (1995) [6], Bhagat et al (1999) Tyagi and patel (2004) ${ }^{[8]}$.

\section{Conclusion}

On the basis of overall assessment of the results of the present investigation on influence of different rooting media and PGR's on rooting and survival of air layering in pomegranate, the following conclusions can be drawn.

1. Use of Coco peat + IBA 1000 ppm for air layering in pomegranate significantly influenced the early root initiation, bulk appearance of roots, primary root, secondary roots, root length, fresh and dry weight of root.

2. It is evident that the use of Coco peat + IBA 1000ppm as a combination of rooting medium for air layering in pomegranate resulted in maximum rooting as well as survival of air layers and more number of healthy air layers was obtained with use of this treatment.

\section{Reference}

1. Chatterjee BK. Rooting of air layers in Jackfruit. Andhra agriculture Journal 1981;28(5,6):265-266.

2. Divekar PB. Studies on vegetative propagation of Karonda (Carisa carandas) A thesis submitted to the Konkan Krishi Vidyapeeth, Dapoli (M.S.) 1984.

3. Kumar K, Syamal MM. Effect of etiolation and plant growth substances on rooting and survival of air layers of guava. Indian Journal of horticulture 2005;62(3):290-292

4. Kumar P, Thakur S, Singh UK, Singh RR. Effect of growth regulators on the rooting and survival of airlayers of jackfruit. Journal of Applied Biology 2004;14(1):39-41.

5. Panse VG, Sukhatme PV. Statistical methods for agricultural workers I.C.A.R. Pub. New Delhi 1967,167174.

6. Sobhana P, Rajgopal R, Sethuraj MR, Vijaykumar KR. A note, on vegetative propagation of Hevea brasiliensis by air layering. Indian Journal of Natural Rubber Research 1995;8(1):70-72.

7. Tryabake SK, Patil MT. Effect of different substrate on rooting and survival of air laers in pomegranate. M.Sc. (Agri.) thesis submitted to M.P.K.V, Rahuri 2002.

8. Tyagi SK, Patel RM. Effect of growth regulators on rooting of air layering of guava (Psidium guajava L.) cv. Sardar guava. Orissa Journal of Horticulture 2004;32(1):58-62. 